\title{
'My Expectations Remain the Same. The Student Has to Be Competent to Practise': Practice Assessor Perspectives on the New Social Work Degree Qualification in England
}

Jo Moriarty, Gillian Maclntyre, Jill Manthorpe, Beth R. Crisp, Joan Orme, Pam Green Lister, Kate Cavanagh, Martin Stevens, Shereen Hussein, and Endellion Sharpe

\section{Summary}

Research has emphasized the importance of practice learning to social work qualifying education but has tended to feature social work educator and student perspectives more strongly than the views of those responsible for assessing students' practice in the field. This article draws on 195 responses to a postal questionnaire sent at two points in time to practice assessors working with students from nine social work qualifying programmes run in six higher education institutions collected as part of the evaluation of the new social work degree qualification in England. While practice assessors described changes in their role and in the opportunities available to students, they 
also emphasized continuities, particularly in the skills that they expected students to possess. The key difficulty they identified was the heavy workload resulting from combining their role as practice assessors with their other responsibilities at work. Increases in the number of social work students and changes to the organization of services are likely to create further pressures on practice assessors. Given that these issues are faced by a number of different professions, the article concludes that there is potential for future studies to look at the experiences of practice educators across different professional qualifying programmes.

Keywords: Practice learning, social work education, survey

\section{Introduction}

Practice learning is widely considered to be the cornerstone of social work education (Parker, 2006) and the experience most likely to be remembered post qualification (Doel and Shardlow, 1996; Papadaki and Nygren, 2006). In the UK, practice assessors play a key role in the assessment of practice learning (Crisp et al., 2006). They work in agencies offering practice learning opportunities to social work students and the term relates to their activities and responsibilities, rather than to any particular qualification (Kearney, 2003).

In the past, it was intended that students on social work qualifying programmes would be supervised by social workers holding the practice teaching award but this proved to be impossible to achieve (Shardlow et al., 2002). One reason for this was the high attrition rate among practice teachers drawn into first line management roles because the award was often seen as a proxy management qualification (Kearney, 2003). This was accentuated by a shortage of good-quality placements (Barker and Ash, 1988; Parsloe, 2001) resulting in students being placed in agencies where they were supervised on a daily basis either by social workers not holding the practice teachers' award or by people from other professional backgrounds. In these instances, overall responsibility for their practice learning rested with experienced freelance, or independent, practice assessors (so-called 'long arm practice teachers') (Karban, 1999). As agencies providing social work have changed to become more multidisciplinary in nature, the trend for practice assessors not to possess a social work qualification is increasing (Laycock et al., 2007) and this model is becoming more prevalent.

This article uses data from 195 practice assessors collected as part of the Department of Health-funded Evaluation of the Social Work Degree Qualification in England (Evaluation of the Social Work Degree Qualification in England Team, 2008a, 2008b). The change to degree level qualifying social work education in England (Department of Health, 2001) was accompanied by an increase in the number of days that students spent in 
practice learning (Department of Health, 2002b) and the establishment of a Practice Learning Taskforce to increase the quantity and quality of practice placements (Department of Health, 2002a). Although the evaluation was a multi-method study, by concentrating solely upon a single data source, we are able to report in more depth and include information not reported elsewhere. The article comes at an important transitional time at which a body of evidence on the changes to practice learning following implementation of the social work degree is emerging (Doel et al., 2004; 2007; Elliott et al., 2005) but the effects of the new post-qualifying framework (General Social Care Council, 2005) on practice education have yet to emerge. It highlights some of the continuities and differences in practice assessors' roles and concludes that strategies aimed at improving practice learning need to give greater recognition to the impact of their dual roles of practice assessor and agency-based professional. As other professions, such as nursing and occupational therapy, are facing similar issues, there is an opportunity for future multidisciplinary research exploring practice education across different professions. Furthermore, the nature of partnerships between higher education institutions (HEIs) and employers and the role played by practice assessors are likely to become increasingly topical in the light of concerns about the quality and quantity of practice placements expressed in the audit of the social work degree (Blewett and Tunstill, 2008) commissioned by the General Social Care Council (GSCC), the body responsible for regulating social work and social care in England.

\section{Background}

Existing research has tended to feature the perspectives of students or social work educators more strongly than those of assessors themselves. This has highlighted variation in assessors' abilities to evaluate different aspects of student learning, such as anti-oppressive practice (Ellis and Thorpe, 1999) or legislation (Preston-Shoot, 2003), and the processes through which they observe students' practice (Humphrey, 2007). Other studies have looked at students' satisfaction with practice learning (Barron, 2004) or its effects in developing their perceptions of competence (Parker, 2006). Concerns have been expressed about the potential for students to be oppressed because they are in positions of structural subordination (Cowburn et al., 2000) and the relationship between student and assessor has been shown to be a crucial factor in the quality of the practice learning environment (Lefevre, 2005).

Assessors themselves have highlighted the satisfactions coming from seeing students develop (Davies and Connolly, 1994; Shardlow et al., 2002). However, they can also face tensions between their roles as practice assessor and employee. Organizational culture has been shown to be an 
important factor in recruiting and supporting practice assessors (Torry et al., 2005) but practice learning may be a low priority for managers concerned with other service delivery priorities (Bhattacharyya et al., 1998). Such issues are not restricted to the UK but are reported elsewhere (Maidment, 2003). At the same time, the costs to the agency of taking students should be acknowledged. In particular, students who perform poorly can pose considerable difficulties because of the additional time needed for support and supervision (Davies and Connolly, 1994).

\section{Methods}

The study methods have been described in detail elsewhere (Orme et al., 2007). In summary, practice assessors who had worked with students from five undergraduate and four postgraduate social work qualifying programmes in six different higher education institutions (HEIs) in England were invited to complete a questionnaire asking about their experiences as a practice assessor, their views of aspects of student performance, the issues they faced as assessors, and their demographic and professional backgrounds. The questionnaire included both open and closed questions. In order to comply with data protection requirements, questionnaires were distributed by practice learning co-ordinators except in one site, where the HEI obtained permission from practice assessors to disclose their details to the research team. They were administered twice-first, in 2006, to those who had worked with students on their first placement (Time One) and, second, in 2007, when they were sent to those working with students on their final placement (Time Two).

The Requirements for Social Work Training (Department of Health, $2002 b$ ) stipulate that students should have experience of working in at least two different practice settings. This prevented our undertaking a classic pre-test/post-test comparison in which the same assessors commented on the same student at two different points in time. It is theoretically possible but unlikely that respondents assessed the same students on their first and final placements. An Australian study (Cooper and Crisp, 1998) found high levels of turnover among field educators, the equivalent of practice assessors, and UK research (Doel et al., 2004; 2007) suggests that different settings are used for first and final placements. Rather, the findings presented here are drawn from repeated cross-sectional data in which different assessors reported on students from a specific programme at differing stages in their learning.

Data were analysed using content analysis (Bryman, 2004) to identify recurring themes across respondents' answers. The chief advantage of this method was that it enabled links to be made between respondents' answers to open-ended questions and other quantifiable data such as their levels of experience or type of practice assessor role. 
Table 1 Characteristics of practice assessors responding to survey

\begin{tabular}{|c|c|c|c|c|}
\hline \multirow[t]{2}{*}{ Characteristics } & \multicolumn{2}{|c|}{ Time One } & \multicolumn{2}{|c|}{ Time Two } \\
\hline & $\%$ & $N$ & $\%$ & $N$ \\
\hline \multicolumn{5}{|l|}{ Gender } \\
\hline Men & 20 & 24 & 13 & 10 \\
\hline Women & 80 & 94 & 86 & 63 \\
\hline \multicolumn{5}{|l|}{ Ethnicity } \\
\hline White & 89 & 105 & 86 & 63 \\
\hline Black and minority ethnic group & 11 & 13 & 14 & 10 \\
\hline \multicolumn{5}{|l|}{ Social work qualification } \\
\hline Yes & 92 & 106 & 95 & 69 \\
\hline No & 8 & 9 & 5 & 4 \\
\hline \multicolumn{5}{|l|}{ Received training as an assessor } \\
\hline Yes & 91 & 115 & 97 & 71 \\
\hline No & 9 & 12 & 3 & 2 \\
\hline \multicolumn{5}{|l|}{ Holds practice teaching award } \\
\hline Yes & 62 & 73 & 55 & 39 \\
\hline No & 38 & 46 & 45 & 32 \\
\hline \multicolumn{5}{|l|}{ Role } \\
\hline Practice assessor & 71 & 85 & 67 & 49 \\
\hline Workplace supervisor & 6 & 7 & 15 & 11 \\
\hline Freelance practice assessor & 20 & 24 & 18 & 13 \\
\hline Mean age & \multicolumn{2}{|c|}{46.3 (SD 9.1) } & \multicolumn{2}{|c|}{46.2 (SD 9.1) } \\
\hline Mean number of years as assessor & \multicolumn{2}{|c|}{5.7 (SD 6.6) } & \multicolumn{2}{|c|}{5.0 (SD 4.8) } \\
\hline Total $n$ & \multicolumn{2}{|l|}{122} & \multicolumn{2}{|l|}{73} \\
\hline
\end{tabular}

Percentages in this and subsequent tables may not total 100 per cent due to rounding.

\section{Findings}

A total of 122 replies were received at Time One and 73 at Time Two. The main reason for this disparity was staffing issues on one site that prevented their circulation. The way that questionnaires were distributed prevented an overall response rate from being calculated but, in the site where questionnaires had been individually posted by the researchers, the response rates were, respectively, 52 and 58 per cent at Times One and Two.

\section{Assessors' backgrounds}

Table 1 presents the demographic and professional backgrounds of assessors returning questionnaires. Their gender, age and ethnic distribution broadly reflects that found in representative samples of social workers (Smyth, 1996; Balloch et al., 1999; Huxley and Evans, 2005). However, with a mean age of $52(\mathrm{SD}=9.1)$, it was striking that freelance practice assessors were significantly older $(F=20.5, p=0.0001)$ than other respondents, whose mean age was $45(\mathrm{SD}=8.4)$. They were also more experienced. On average, they had spent almost nine years $(\mathrm{SD}=7.1)$ as an assessor compared with four years $(\mathrm{SD}=5.1)$ among practice assessors 
and workplace supervisors $(F=18.9, p=0.0001)$. This is in keeping with the expectation that freelance assessors will have considerable experience in practice education (Skills for Care West Midlands, 2008). As Table 1 shows, almost all the assessors returning questionnaires were qualified social workers who may have been more interested in, or felt more qualified to comment on, social work education.

\section{Training to be an assessor}

Table 1 shows that the overwhelming majority of respondents had received specific training to be an assessor. In some cases, it consisted of short introductory or refresher courses:

All supervisors who take students are encouraged to attend the five-day supervision and assessment skills course put on by the university (Time Two, PA 49).

However, the majority held the Practice Teaching Award. A further seventeen respondents were undertaking a post-qualifying award in practice education. This could pose difficulties if deadlines for completing their own course work and students' reports coincided:

On top of my own course work and caseload, the additional work required was considerable and both the [student's] report and my portfolio had to be submitted at almost the same time (Time One, PA 60).

\section{Practice changes}

Respondents were strongly in favour of the requirement for 200 days to be spent on practice placements. Around a quarter of Time One respondents and two-thirds of Time Two respondents answering an open question about positive outcomes of the degree made comments about this increase and what they saw as a greater emphasis on practice:

The longer placements enable students to have a better understanding of how to do the job (Time Two, PA 53).

At the same time, they were conscious of the pressures that this placed both on them and the agency in which they worked:

I felt that the university had little understanding of the impact of longer placements - [over 100 days] felt very long for my team-we were short staffed (Time Two, PA 13).

Longer placements - I really [emphasis original] felt the last 35 days [of the 100-day placement] and was glad [when it] ended (Time Two, PA 03).

In common with other research (Doel et al., 2004; 2007), the increase in practice learning days combined with an increase in student numbers was seen to have placed pressures on assessors to take more students: 
Table 2 Agencies in which assessors were located

\begin{tabular}{|c|c|c|c|c|}
\hline \multirow[t]{2}{*}{ Sector } & \multicolumn{2}{|c|}{ Time one } & \multicolumn{2}{|c|}{ Time two } \\
\hline & $\%$ & $N$ & $\%$ & $N$ \\
\hline Local authority & 49 & 60 & 63 & 46 \\
\hline Hospital & 3 & 4 & 6 & 4 \\
\hline Other health based agency & 2 & 2 & 1 & 1 \\
\hline Voluntary sector & 25 & 31 & 14 & 10 \\
\hline Private sector & 7 & 8 & 7 & 5 \\
\hline Education & 2 & 2 & 1 & 1 \\
\hline Housing & 3 & 3 & 0 & 0 \\
\hline Other & 3 & 3 & 0 & 0 \\
\hline Joint & 7 & 9 & 8 & 6 \\
\hline Total $n$ & & 122 & & 73 \\
\hline
\end{tabular}

There has been a general encouragement to recruit [and train] more practice [assessors] and to develop better and more rounded placement settings [but the programme] has both a deficit in student support staff and good placements. This has meant that pressure [is] placed on [us] to take on students. We get a lot of last minute requests (Time Two, PA 12).

\section{Agencies in which assessors were located}

One longstanding response to placement shortages has been to widen the pool of organizations taking students. Other evaluation data collected from students via a series of online surveys (Evaluation of the Social Work Degree Qualification in England Team, 2008a) suggested that only around half of first and second placements were in traditional local authority fieldwork teams in children's or adult services. Table 2 shows the sector in which Time One and Time Two respondents were located. It suggests that while the majority of placements continued to take place in statutory local authority adults or children's services, an increasingly high proportion were in the voluntary and private sectors. These included fostering and adoption agencies, advocacy schemes, hospices and other communal establishments, such as residential schools or private care homes. The higher proportion of Time Two respondents in statutory agencies is consistent with other research (Doel et al., 2004; 2007) reporting that final placements are more likely to take place in the statutory sector.

While many respondents thought that students benefited from opportunities to work in a range of settings, some freelance assessors were concerned about the quality of some of the learning opportunities. Drawing on her experiences with programmes in three different HEIs, a freelance assessor regretted the existence of placements that:

Still don't understand the needs of social work students [and that] obviously only do it for the money and give minimum supervision and opportunities (Time Two, PA 27). 


\section{Working with other professionals}

Policy objectives (HM Government, 2005; Department of Health, 2008) anticipate greater working together among different public service professionals. Eighty-one per cent of Time One and 89 per cent of Time Two respondents reported that their agency offered students experience of inter-agency working. Examples included work with housing and benefits agencies or, as Table 2 shows, in integrated agencies, most usually with the National Health Service. Respondents reported that almost all these opportunities were already in place and not developed specifically for the new degree.

\section{Service user involvement}

Service users and carers had been involved in assessing practice learning under the DipSW but not consistently (Edwards, 2003) so the requirement for service user and carer involvement in all aspects of the degree (Department of Health, 2002b, p. 9) was an important change.

The most frequent type of involvement was informal feedback, which was reported by around 90 per cent of respondents at Times One and Two. However, people using services were also involved in formal assessment:

Service users and carers have completed [a] 'compliments form' and... feedback forms relating to direct observations of students' practice (Time Two, PA 52).

While fewer than half of Time One respondents reported this type of involvement, by Time Two, the proportion had risen to almost two-thirds.

Overall, more than a third of respondents at both Times One and Two reported that service user and carer involvement in practice education had increased since the new degree but the majority thought it had remained unchanged. It was noticeable that assessors working in services for adults were significantly (Cramer's $\mathrm{V}=0.319, p=0.013$ ) more likely to report that service user and carer participation in practice settings had increased than their counterparts working with children. As one assessor acknowledged:

This has always been a difficult area for students working in child protection and the degree has made [service user involvement] a requirement, which can be difficult (Time Two, PA 25).

\section{Changes to role of practice assessor}

At Time One, only 15 per cent of respondents had not worked with DipSW students. This meant that the overwhelming majority were able to compare their roles assessing DipSW and degree students. Although it must be 
acknowledged that there is considerable variation in the ways in which different programmes operationalize methods of assessment, respondents to these surveys considered that the advent of the degree had brought greater clarity about the assessor's role, placed more onus upon students to show what they had achieved and simplified assessment forms. Over a quarter of respondents saw these changes as entirely positive:

The final report is much shorter and structured [compared with] the DipSW report which was longer and took a lot of time to write (Time One, PA 78).

However, a similar proportion reported mixed experiences:

[With] the new assessment framework, the responsibility rests on students to provide evidence-which is better. However, I have had to work at a more basic level with students on their 'people' skills and values (Time One, PA 76).

Just under a quarter of respondents answered 'don't know', presumably because they thought that it was too early to assess the changes. This left just four respondents, who considered that the changes were 'negative'. Among these was a freelance assessor with over sixteen years' experience:

I have been dismayed by the change from 'teacher' to 'assessor' . . . Identifying and confirming evidence takes up a huge amount of time that could be better spent reflecting on the student's practice and helping her to relate it to theory (Time One, PA 69).

At Time Two, the proportion of respondents who had not assessed DipSW students was over twice as high, meaning that proportionally fewer were able to compare the two. Around a third of respondents still rated the changes as 'positive', but over half thought they were 'mixed'. By now, no respondents were undecided and, once more, the number of respondents choosing the 'negative' option was very low, rising from four to six people.

Arguably, the increase in the proportion of respondents choosing 'mixed' reflected the challenges in encapsulating the complexities of student performance at final placement and the reduction in respondents reporting they were undecided. However, one respondent considered that the GSCC and programmes themselves now had higher expectations of students' performance. This, in turn, placed greater responsibilities on the assessor:

GSCC and universities have more expectations of students. This makes [the] practice teacher's (sic) role more complex and time consuming but the expectations are also made much more explicit and this is helpful (Time Two, PA 26).

\section{Balancing classroom and practice learning}

One of the issues reported most often by respondents was their concern that practice learning should not be seen as less important than academic work. In most instances, combining the two was seen to bring clear educational benefits: 
Student had to do a lot for their portfolio, as well as work/casework on placement [and] course work to be completed for uni[versity]. [It] puts a lot of pressure on them... I do feel however that splitting the time between one day at [HEI] and four days on placement does have its uses, particularly if [content of lectures] coincides with [the] agency setting.... It helps [students] to relate theory to practice (Time Two, PA 23).

However, assessors were less sympathetic if they considered that students had deliberately chosen to prioritize work that would gain higher academic grades over work that was assessed as pass/fail, as is the case with practice learning on many social work programmes:

[Barrier] was student's attitude. Achieved pass but only just about met criteria. She seemed to want to do the minimum possible to pass (Time Two, PA 61).

In keeping with earlier research (Davies and Connolly, 1994) on the costs to the agency of taking students whom they consider are unlikely to meet the required standards, they also considered that students' suitability for practice learning should be assessed rigorously:

[Difficulty] is being asked to take 'failing' students when it is clear the problems are dire-e.g. bad practice, poor English/grammar etc. (Time Two, PA 52).

\section{Expectations of students and student performance}

Respondents were also asked to compare degree and DipSW students in terms of their preparedness for practice, performance in practice learning, theoretical knowledge, approach to equalities issues and communication skills. The results are shown in Table 3.

None of these changes was statistically significant, possibly because of the small number of responses at Time Two. However, the assessors' comments provided some important contextual information for these findings, and this is why they are discussed in more detail.

First, Table 3 shows that at both Times One and Two, the majority of respondents thought that DipSW and degree students performed similarly. They stressed that there was a common baseline from which all students had to be assessed, whichever qualifying programme they were undertaking:

My expectations remain the same. The student has to be competent to practise (Time Two, PA 68).

Crucial to meeting these expectations was the degree to which respondents considered student performance and attitudes were enmeshed. At Time One, when asked an open question about the three main barriers they faced in terms of implementing good-quality practice learning opportunities for students on the new degree, the most frequent comment, mentioned by a quarter of all those answering this question, was negative 
Table 3 Respondents' ratings of performance of degree and DipSW students

\begin{tabular}{|c|c|c|c|c|}
\hline \multirow[t]{2}{*}{ Student performance } & \multicolumn{2}{|c|}{ Time One } & \multicolumn{2}{|c|}{ Time Two } \\
\hline & $\%$ & $N$ & $\%$ & $N$ \\
\hline \multicolumn{5}{|c|}{ Preparedness for placement } \\
\hline Better & 14 & 14 & 20 & 9 \\
\hline Same & 52 & 48 & 58 & 26 \\
\hline Worse & 34 & 32 & 22 & 10 \\
\hline \multicolumn{5}{|c|}{ Performance in practice learning } \\
\hline Better & 13 & 11 & 16 & 7 \\
\hline Same & 65 & 56 & 66 & 29 \\
\hline Worse & 22 & 19 & 18 & 8 \\
\hline \multicolumn{5}{|l|}{ Theoretical knowledge } \\
\hline Better & 30 & 28 & 42 & 18 \\
\hline Same & 52 & 48 & 49 & 21 \\
\hline Worse & 17 & 16 & 9 & 4 \\
\hline \multicolumn{5}{|l|}{ Approach to equalities } \\
\hline Better & 14 & 12 & 14 & 6 \\
\hline Same & 72 & 64 & 74 & 32 \\
\hline Worse & 14 & 13 & 12 & 5 \\
\hline \multicolumn{5}{|l|}{ Communication skills } \\
\hline Better & 12 & 11 & 16 & 7 \\
\hline Same & 70 & 62 & 72 & 31 \\
\hline Worse & 18 & 16 & 12 & 5 \\
\hline Total $n$ & & 93 & & 45 \\
\hline
\end{tabular}

The base numbers in this table differ from those in Tables 1 and 2 because the questions were only asked of respondents who had supervised both DipSW and degree students.

student attitudes. A frequent example of what these were perceived to be was students' failure to engage with a practice learning experience because it was not taking place in their chosen setting. In the tactful words of one assessor in a substance misuse agency, a lack of 'student compatibility' could prevent them from benefiting fully from what she saw as the valuable opportunities to work with maternity services, on a needle exchange scheme and in structured day-care. However, by Time Two, where assessors were commenting on their experiences of students on their final placement, the proportion of assessors commenting on negative attitudes among students had fallen to 11 per cent.

While social work educators (Cowburn et al., 2000; Humphrey, 2007) have commented on the risk of students being oppressed, the following comment gives a different sense of the power nexus in practice learning settings:

I expect all students whatever their degree/DipSW etc to have a basic understanding of their role and what social work practice with regard to protecting children involves. The student was not prepared for placement and, with hindsight, appeared to dictate to the university (Time Two, PA 39).

Another explanation offered by assessors for their ratings was the impact of greater numbers of degree students with little or no experience in social 
care. However, this was seen as primarily affecting students on their first placement:

This particular student had no previous experience of older people or care management. Therefore, the first part of her placement was used to provide her with the learning opportunities necessary to understand care management (Time One, PA 77).

By the final placement, this difference had disappeared:

My experience is that final year students on both degree and DipSW have similar preparedness. There is a difference between degree students ... and DipSW students on first placement (Time Two, PA 25).

The final issue emerging from Table 3 is the variation in ratings across different aspects of performance. The rating of degree students' theoretical knowledge at Time Two is particularly striking and is consistent with the overall benefits that it was hoped a move to degree-level professional education would bring (Orme, 2000; Preston-Shoot, 2000). However, compared with basic communication skills and an understanding of equalities issues in which the greatest similarities were seen between degree and DipSW students' performance, there was greater variation in assessors' ratings of their theoretical knowledge and preparedness for placement. This is in keeping with existing research demonstrating that skill acquisition does not progress evenly and that the most complex skills, such as the ability to translate theory into practice, are likely to take longest to develop (pace Fook et al., 1997, 2000; Fook, 2002). This was where assessors saw their role as central:

Students have limited capacity to link theory into practice. Supervision focuses on this transfer, rather than [on] issues of social work interventions (Time Two, PA 14).

It is also important to stress that assessors believed that variation between individual students could not be eliminated. A freelance assessor who had supervised ten students from programmes in three different universities in the previous year explained:

There are good and bad students on both [DipSW and degree] courses and I have had excellent students... and bad students on both (Time Two, PA 21).

\section{Support for assessors}

This final section considers assessors' views on the types and adequacy of the support that they received. At Time One, 59 per cent of assessors considered that the levels of support available to them on DipSW and degree programmes were the same, 13 per cent thought they had improved, 6 per cent thought that they had worsened and 18 per cent were unsure. At Time Two, 25 per cent thought they had improved, and just two 
respondents thought they had deteriorated. At both Times One and Two, line managers were the most frequently reported source of support. Colleagues and other assessors were also mentioned.

However, it also appeared that there was a role for more tailored interventions. These were felt to be needed at times of organizational change:

The number of reorganizations that staff are coping with [creates] constant change in the practice environments (Time Two, PA 49).

They might also be used to address the needs of under-represented groups. Table 1 shows that black practice assessors were in a minority among those returning questionnaires. Consistent with existing work on the need for mentoring and support groups specifically for black workers as a way of improving anti-discriminatory practice within organizations and resolving negative experiences (Singh, 2006; Graham, 2007), one respondent wrote that she valued attending a practice assessors' support group but wished that there was a group specifically for black practice assessors in her area.

Freelance assessors were another group for whom additional support needs were identified:

I think freelance practice assessors should be offered some kind of supervision sessions from the university. It might only be a couple of sessions on a shorter placement but on a longer final placement, freelance practice assessors have no one except each other (Time Two, PA 27).

Practice learning co-ordinators were mentioned as providing support by around half of the respondents:

Placement co-ordinator runs support groups, has books to lend, and offers advice. University has training days (Time Two, PA 22).

As others have noted, the development of a 'reading' culture among practitioners is under-developed (Horder, 2007). Unsurprisingly, support in this regard was welcomed, as was the opportunity to attend workshops and training run by the HEI:

[Universities] have very [well] organized [and] planned workshops. This enables you to share your own experiences and knowledge (Time Two, PA 21).

However, assessors were not always able to find the time to attend workshops of this sort. An assessor in a rural area praised the tutor who, knowing that she would be unable to travel to workshops held in the HEI, had kept in touch by e-mail.

Support from the HEI was seen as particularly important by those who were comparatively new to practice education. For example, one respondent in her first year as a practice assessor wrote:

Would have liked more support from my student's university tutor in relation to expectations of my role. Little guidance given on writing the student reports. Would have liked more details about the student's 
academic programme, so that I could make better links to the practice training (Time One, PA 62).

By contrast, another assessor in a similar position in terms of experience reported:

By mid point the student was failing and I arranged a 'four way' meeting [with student, self, tutor and manager]. From that meeting a viable plan was agreed which put the placement on track again. This plan demanded a high level of commitment from all parties in addition to increased time allocation. I was pleased at the level of support I received (Time One, PA 83).

However, by far the most frequently reported difficulty was the lack of 'workload relief' for those who were working as assessors in the form of a reduction in caseload. This was mentioned by 25 per cent of respondents at Time One and 42 per cent at Time Two, making it the issue that was their greatest concern:

[Lack of] recognition of the amount of time required by assessors to take on a student-e.g. [by] adjustment to case[load] level [and the impact of] other commitments by assessors, e.g. ASW [approved social worker] role not taken into account (Time Two, PA 70).

Different agencies have different ways of using the fees that they receive for taking students. One agency assessor saw additional payments to practice assessors as partial recompense for time spent supervising students in addition to their contracted hours of employment:

[Barrier was] decision to remove remuneration from practice teachers.

[I] received $£ 250$ per student [with the DipSW], now nothing. If [you are]

a senior practitioner, you are expected to take a student regardless

(Time Two, PA 67).

\section{Discussion}

This article has used responses to a postal questionnaire administered at two time points to practice assessors on nine social work programmes to discuss some of the issues that they faced and their suggestions for improvements.

Although further work would be required to identify the representativeness of this sample, the demographic and professional backgrounds of respondents in this study suggest that, despite the increasing diversity among those undertaking practice assessor roles, there is still a body of experienced practitioners concerned about, and committed to, social work education.

Practice assessors broadly welcomed the changes to practice learning created by the introduction of the social work degree. There was little evidence of practitioners associating the introduction of graduate education with a move away from core activities, as in the widespread media coverage 
of graduate nurses being 'too posh to wash' (Hooper, 2004; Scott, 2004). Degree students were seen as performing broadly similarly to DipSW students, particularly on final placement, consistent with the evidence of gradual socialization into the profession (Fook et al., 2000).

Research (Edwards, 2003; Levin, 2004) has shown that service user and carer involvement in assessing practice learning has been uneven. Although there were signs of a clear trend towards greater involvement, it appeared that the process has been incremental and continues to be more informal than systematic. This raises the risk of dissonance between more progressive educational curricula and more conservative practices in agencies (Lewis and Bolzan, 2007), and highlights the benefits of systems that support greater involvement of people using services and carers in practice learning (e.g. Elliott et al., 2005).

Although students may face difficulties through being in a position of structural subordination to that of assessors (Cowburn et al., 2000; Humphrey, 2007), the classic study of receptionists in primary care (Arber and Sawyer, 1985) reminds us how the lines of power and structural authority are not always parallel. Assessors highlighted the difficulties of dealing with students who did not wish to work in a particular agency or who did not engage fully with practice learning. While line managers and colleagues were sources of support in these situations, support groups and workshops run by HEIs were also seen as offering benefits, especially to less experienced assessors.

However, the most important issue raised by assessors was the lack of 'workload relief' in recognition of the time they spent supervising and supporting students. As Shardlow and colleagues (2002) have observed, highlighting the seeming intractability of this issue, the satisfactions from being an assessor, such as pleasure in seeing new recruits develop, are unlikely to be enough without the structural supports to facilitate this role.

Finally, it has been pointed out that surprisingly little research has taken place into what makes practice learning effective (Parker, 2006). The expanding literature on practice learning in other professions, such as occupational therapy (Wood, 2005), physiotherapy (Morris, 2007) and nursing (Anderson and Kiger, 2008; Pearcey and Draper, 2008), has also highlighted the position of students' learning in multidisciplinary settings and receiving supervision from a person with a different professional background. These professions also face difficulties in securing practice placements (Craik and Turner, 2005; Murray et al., 2005). The existence of similar issues across other professions combined with an increasing tendency for practice learning to take place in multidisciplinary settings highlights the potential opportunities for research exploring the experiences of practice assessors from differing professional backgrounds. 


\section{Acknowledgements}

Since this article was submitted, the research team have been saddened by the death of their colleague and co-researcher, Kate Cavanagh (19512008), and wish to recognize her contribution to the research on which this article is based. We thank the Department of Health for funding this research and acknowledge the help of the project Reference Group, the Advisory Group of people with experience of using services and/or caring and the Evaluation Co-ordinator, Marie McNay. We especially thank the practice assessors taking part in these surveys and all those responsible for contacting them. The views expressed in this article are those of the authors and not necessarily of the Department of Health.

\section{References}

Anderson, E. E. and Kiger, A. M. (2008) “"I felt like a real nurse”: Student nurses out on their own', Nurse Education Today, 28(4), pp. 443-9.

Arber, S. and Sawyer, L. (1985) 'The role of the receptionist in general practice: A “dragon behind the desk"?', Social Science \& Medicine, 20(9), pp. 911-21.

Balloch, S., McLean, J. and Fisher, M. (eds) (1999) Social Services: Working Under Pressure, Bristol, The Policy Press.

Barker, R. and Ash, A. (1988) 'Providing a placement service an experiment in North Wales', Practice, 2(1), pp. 47-57.

Barron, C. (2004) 'Fair play: Creating a better learning climate for social work students in social care settings', Social Work Education, 23(1), pp. 25-37.

Bhattacharyya, M., Harwood, P., Hayto, A. and Seden, J. (1998) 'The role of the senior practice teacher in DipSW delivery (or the stitching in the patchwork of local authority placements)', Practice, 10(3), pp. 55-64.

Blewett, J. and Tunstill, J. (2008) Fit for Purpose? The Social Work Degree in 2008, London, General Social Care Council.

Bryman, A. (2004) Social Research Methods, 2nd edn, Oxford, Oxford University Press.

Cooper, L. and Crisp, B. R. (1998) 'Field educator turnover: A challenge to the quality of field education', Asia Pacific Journal of Social Work, 8(1), pp. 89-105.

Cowburn, M., Nelson, P. and Williams, J. (2000) 'Assessment of social work students: Standpoint and strong objectivity', Social Work Education, 19(6), pp. 627-37.

Craik, C. and Turner, A. (2005) 'A chronic shortage of practice placements: Whose responsibility?', British Journal of Occupational Therapy, 68(5), p. 191.

Crisp, B. R., Lister, P. G. and Dutton, K. (2006) 'Not just social work academics: The involvement of others in the assessment of social work students', Social Work Education, 25(7), pp. 723-34.

Davies, M. and Connolly, J. (1994) 'The price of taking students: An exploratory costbenefit analysis in social work agencies', Health and Social Care in the Community, 2(6), pp. 339-46.

Department of Health (2001) Press Release 2001/0154: Radical Reforms to Social Work Training to Raise Social Care Standards, London, Department of Health.

Department of Health (2002a) Press release 2002/0241: New social work degree will focus on practical training, London, Department of Health. 
Department of Health (2002b) Requirements for Social Work Training, London, Department of Health.

Department of Health (2008) Putting People First: Working to Make It Happen: Adult Social Care Workforce Strategy - Interim Statement, London, Department of Health.

Doel, M. and Shardlow, S. (1996) The New Social Work Practice, Aldershot, Arena.

Doel, M., Deacon, L. and Sawdon, C. (2004) An Audit of Models of Practice Learning in the New Social Work Award, Sheffield, Sheffield Hallam University.

Doel, M., Deacon, L. and Sawdon, C. (2007) 'Curtain down on Act One: Practice learning in the first year of the new social work award', Social Work Education, 26(3), pp. 217-32.

Edwards, C. (2003) 'The involvement of service users in the assessment of Diploma in Social Work students on practice placements', Social Work Education, 22(4), pp. 341-9.

Elliott, T., Frazer, T., Garrard, D., Hickinbotham, J., Horton, V., Mann, J., Soper, S., Turner, J., Turner, M. and Whiteford, A. (2005) 'Practice learning and assessment on BSc (Hons) Social Work: "Service user conversations"“, Social Work Education, 24(4), pp. 451-66.

Ellis, P. and Thorpe, A. (1999) 'Transition from qualifying to post qualifying level: A research based evaluation', Issues in Social Work Education, 19(Autumn), pp. 3-22.

Evaluation of the Social Work Degree Qualification in England Team (2008a) Evaluation of the New Social Work Degree Qualification in England. Volume 1: Findings, London, King's College London, Social Care Workforce Research Unit.

Evaluation of the Social Work Degree Qualification in England Team (2008b) Evaluation of the New Social Work Degree Qualification in England. Volume 2: Technical Appendix, London, King's College London.

Fook, J. (2002) 'Towards a theory of social work expertise', Qualitative Social Work, 1(1), pp. 79-95.

Fook, J., Ryan, M. and Hawkins, L. (1997) 'Towards a theory of social work expertise', British Journal of Social Work, 27(3), pp. 399-417.

Fook, J., Ryan, M. and Hawkins, L. (2000) Professional Expertise: Practice, Theory and Education for Working in Uncertainty, London, Whiting \& Birch.

General Social Care Council (2005) Post-Qualifying Framework for Social Work Education and Training, London, General Social Care Council.

Graham, M. (2007) Black Issues in Social Work and Social Care, Bristol, The Policy Press.

HM Government (2005) Children's Workforce Strategy: A Strategy to Build a WorldClass Workforce for Children and Young People, London, Department for Education and Skills.

Hooper, V. D. (2004) 'The future of nursing: Are we "too posh to wash"?', Journal of PeriAnesthesia Nursing, 19(4), pp. 292-4.

Horder, W. (2007) "'Reading” in professional practice: How social work practice assessors access knowledge and information', British Journal of Social Work, 37(6), pp. 1079-94.

Humphrey, C. (2007) 'Observing students' practice (through the looking glass and beyond)', Social Work Education, 26(7), pp. 723-36.

Huxley, P. and Evans, S. (2005) Social Work in Wales: A Profession to Value: The Report of the ADSS-Led Multi-Agency Group on the Recruitment and Retention of Local Authority Social Workers in Wales, Cardiff, ADSS Cymru.

Karban, K. (1999) 'Long-arm practice teaching for the diploma in social work: The views of students and practice teachers', Social Work Education, 18(1), pp. 59-70. 
Kearney, P. (2003) A Framework for Supporting and Assessing Practice Learning, London, Social Care Institute for Excellence.

Laycock, C., Walker, L. and Heath, L. (2007) Examining the Experiences of Practice Teachers Who Are Not Social Workers, Sheffield, SYNEM Voluntary Consortium for Social Work Education.

Lefevre, M. (2005) 'Facilitating practice learning and assessment: The influence of relationship', Social Work Education, 24(5), pp. 565-83.

Levin, E. (2004) Involving Service Users and Carers in Social Work Education, London, Social Care Institute for Excellence.

Lewis, I. and Bolzan, N. (2007) 'Social work with a twist: Interweaving practice knowledge, student experience and academic theory', Australian Social Work, 60(2), pp. 136-46.

Maidment, J. (2003) 'Problems experienced by students on field placement: Using research findings to inform curriculum design and content', Australian Social Work, 56(1), pp. 50-60.

Morris, J. (2007) 'Factors influencing the quality of student learning on practice placements', Learning in Health and Social Care, 6(4), pp. 213-19.

Murray, C., Borneuf, A. M. and Vaughan, J. (2005) 'Working collaboratively towards practice placements', Nurse Education in Practice, 5(3), pp. 127-8.

Orme, J. (2000) 'Social work: "The appliance of social science"-A cautionary tale', Social Work Education, 19(4), pp. 323-34.

Orme, J., MacIntyre, G., Green Lister, P., Cavanagh, K., Crisp, B. R., Hussein, S., Manthorpe, J., Moriarty, J., Sharpe, E. and Stevens, M. (2007) 'What (a) difference a degree makes: The evaluation of the new social work degree in England', British Journal of Social Work Advance Access published August 14, 2007, 10.1093/bjsw/ bcm095.

Papadaki, V. and Nygren, L. (2006) “'I'll carry this experience with me throughout my studies and future career": Practice tutorials and students' views on social work in Iraklio, Greece', Social Work Education, 25(7), pp. 710-22.

Parker, J. (2006) 'Developing perceptions of competence during practice learning', British Journal of Social Work, 36(6), pp. 1017-36.

Parsloe, P. (2001) 'Looking back on social work education', Social Work Education, 20(1), pp. 9-19.

Pearcey, P. and Draper, P. (2008) 'Exploring clinical nursing experiences: Listening to student nurses', Nurse Education Today, 28(5), pp. 595-601.

Preston-Shoot, M. (2000) 'Stumbling towards oblivion or discovering new horizons? Observations on the relationship between social work education and practice', Journal of Social Work Practice, 14(2), pp. 87-98.

Preston-Shoot, M. (2003) 'Teaching and assessing social work law: Reflections from a post-qualifying programme', Social Work Education, 22(5), pp. 461-78.

Scott, H. (2004) 'Are nurses "too clever to care" and "too posh to wash"?', British Journal of Nursing, 13(10), p. 581.

Shardlow, S. M., Nixon, S. and Rogers, J. (2002) 'The motivation of practice teachers: Decisions relating to involvement in practice learning provision', Learning in Health and Social Care, 1(2), pp. 67-74.

Singh, G. (2006) Developing and Supporting Black and Minority Ethnic Practice Teachers and Assessors, London, Practice Learning Taskforce.

Skills for Care West Midlands (2008) Guidance for Employing Independent Practice Assessors, Birmingham, Skills for Care West Midlands. 
Smyth, M. (1996) Qualified Social Workers and Probation Officers, London, Office for National Statistics Social Survey Division.

Torry, B., Furness, S. and Wilkinson, P. (2005) 'The importance of agency culture and support in recruiting and retaining social workers to supervise students on placement', Practice, 17(1), pp. 29-38.

Wood, A. (2005) 'Student practice contexts: Changing face, changing place', British Journal of Occupational Therapy, 68(8), pp. 375-8. 